SEMANTIC PLAY AND POSSIBILITY

Invited Contribution

\title{
Heutagogy: \\ A Child of Complexity Theory
}

\author{
STEWART HASE AND CHRIS KENYON \\ Southern Cross University (Australia)
}

One of the great joys of being an academic is that you get to play in the world of ideas and words. It is like being invited to get into your favourite sand pit every day and fool around and see what happens. One of the problems with this, however, is that sometimes people ask you to explain the curious sandcastle you built or that odd looking shape in the corner. As those of you who have a psychological interest might know, the psychoanalytically minded in the profession make a lot of what we do in sand pits and the things we create. They are a very symbolically minded lot. We mention this because what follows is very much a child of our bias, world view, experience and, perhaps, deep unconscious. Chris is an educator, researcher and consultant known for his work in education and culture through his book, 'More than G'day'. Stewart is, variously, an academic, consultant, trainer, psychologist, and psychotherapist.

Both of us had been interested for a while in complex adaptive systems and had played a lot with the systems thinking of Bertanafly (1950), Ackoff and Emery (1972), Fred Emery (1971-1986), and Emery and Trist (1965), for example. For the most part they conceptualised the differential nature of environments and how systems and environment could influence each other. Bertanafly, in particular, challenged the notion that systems are always seeking equilibrium and do in fact adapt to external change. Complexity Theory 
seemed to us to be a natural progression to this theoretical development, in tune with the functioning of the modern world. More importantly, given our interest in learning, a number of complexity theorists had already pointed out its implications for learning (e.g., Davis and Sumara 1997; Doll 1989; Doolittle 2000). The notions of change or learning and bifurcation as being natural phenomena that result from stress on the system was particularly appealing. As educators, and me as a psychologist and psychotherapist, it had become obvious to us (and many constructivists around the globe I am sure) that people only change in response to a very clear need. This usually involves distress such as confusion, dissonance, and fear or a more positive motive such as intense desire. The satiated and the comfortable are less likely to make a behavioural change no matter what others may desire and we'll come back to this later in relation to teacher-centred approaches to learning.

We also like to make the distinction between knowledge and skill acquisition and learning. We see these as quite different processes. Knowledge and skills or competencies can be acquired and even reproduced. But this is not learning at a deeper cognitive level. Learning is an integrative experience where a change in behaviour, knowledge, or understanding is incorporated into the person's existing repertoire of behaviour and schema (values, attitudes and beliefs). For example, it is possible to acquire a set of competencies that one can repeat in familiar or known circumstances. However, if learning has taken place, competencies can also be repeated and even adapted in unfamiliar, unanticipated situations.

Against this background it appeared to us that there were some deficiencies with the existing notions of pedagogy and andragogy. While Malcolm Knowles (Knowles 1970) contributed greatly to our understanding of the limitations of pedagogy when it came to adult learning by defining andragogy, we thought that andragogy did not go far enough. Any examination of learning experiences and curricula designed around andragogical principles certainly demonstrated the capacity for linking into the adult experience and recognised the advantages of self-directed learning. However, curricula were still very much teacher-centric with little opportunity for any real involvement at a micro or even macro level by the learner.

So, over a bottle of a nice crisp white wine one cold Canberra evening, Chris and I described the notion of self-determined learning that best described an extension to pedagogy and andragogy. Chris eventually came up with the term heutagogy, which is derived from the ancient Greek for 'self' with some adjustments and the 'agogy' added. Heutagogy is concerned with learner-centred learning that sees the learner as the major agent in their own learning, which occurs as a result of personal experiences. The teacher might think that he or she can control the learning experience but 
we think the teacher's role is limited to the transfer of knowledge and skills. As well as being an agent in their own learning, it is impossible to predict the extent and effect of bifurcation. Hence, the curriculum and learning activities may become increasingly irrelevant at any point in the so called 'learning process'.

Since the initial paper there has been a growing interest in the concept that has resulted in some research and a number of theoretical papers looking at how heutagogy might be further conceptualised and, more importantly, applied in learning experiences. We'd like to quickly review where the journey has gone thus far.

As noted above, we contextualised heutagogy with reference to complexity theory (Hase and Kenyon 2000; Hase 2002). It thus seemed a natural progression for us to examine a potential link between heutagogy and action research (and necessarily to action learning but we'll refer here just to action research). Stimulated by her doctoral studies Renata Phelps and I (Phelps and Hase 2002) wrote a paper describing what was for us a natural connection between action research and complexity theory. It seemed to us that action research provides the flexibility of being able to try and understand unpredictable and complex social phenomena. In addition both complexity theory and action research emphasise the emergent nature of learning. We'll leave you to read the paper if you'd like to see the connections.

It was then a simple step to start thinking about how action research (and action learning) might fall under the ways in which self-determined learning might take place (Hase 2004; Tay and Hase 2004). Action research allows experimentation with real world experience where learning is in the hands of the participants. This learning can then be tested in subsequent learning cycles. This is as close to real world learning as one can get in a controlled setting where there is a legitimate observer who is also a participant and learner all at the same time. In fact we have been able to document how doctoral students undertaking action research theses have progressed from pedagogical, then andragogical to heutagogical learning in the course of their research (Hase, Tay and Goh 2006; Sankaran, Hase, Dick and Davies 2007). This has been one of the few research projects conducted to investigate the relevance of heutagogy in understanding the learning experience.

Another way in which heutagogy and complexity theory have been connected conceptually is through the idea of capability (Phelps and Hase 2002; Phelps, Hase and Ellis 2005; Kenyon and Hase 2001; Hase and Kenyon 2003; Hase and Tay 2004; Hase 2002;). Capability is a holistic attribute and concerns the capacity to use one's competence in novel situations rather than just the familiar, a justified level of self-efficacy for dealing with novel problems, having appropriate values, being able to work in teams, and knowing how to learn (Hase 2002; Stephenson 1994). It is posited that capable people are more likely 
to be able to manage the world envisaged by complexity theory. In support of this contention, a recent study has demonstrated how dimensions of capability delimited the practice of advanced nursing practitioners in complex health situations (Gardner, Hase, Gardner, Dunn and Carryer 2007).

We have also been particularly interested in how heutagogical approaches might in fact develop capability among people in workplaces (Hase and Kenyon 2003; Hase and Davis 1999; Kenyon and Hase 2001). The competency movement has dominated much of the vocational education and training agenda in Australia and other countries such as New Zealand and the UK. While competencies (knowledge and skills) are obviously essential for effective functioning in workplaces they are concerned with prior ability in known contexts. Capability, however, is concerned with unknown contexts that extend beyond competence. Modern workplaces are complex adaptive systems that provide continuous and rapidly changing contexts. Our research and thinking has concerned how the self-determined learning that occurs in the normal course of work leads to capability can be understood and harnessed. In response to this Wilmott and Barry (2002) found in a review of vocational education and training that there has been a shift in the sector from pedagogical to heutagogical approaches to learning.

It is not surprising that this same thinking in relation to heutagogy has been applied to the developing world of online and e-learning (Albon 2006; Ivan 2006; Keogh 2005) and the transformation of learning in the online environment (Idrus and McComas). It is also encouraging to see that Heutagogy has also been referred to in a number of other contexts examining learning such as: early childhood teaching (Ashton and Newman 2006); problem based learning in the health sector (Kavanagh and Nicol 2007); technology education (Eberle and Childress 2007; ethics (Simms 2003); and credentialing (Olliges and Mahfood 2004).

Thus far there appears, potentially to be a number of ways in which heutagogical thinking might be applied to designing learning processes:

- Recognition of the emergent nature of learning and hence the need for a 'living' curriculum that is flexible and open to change as the learner learns;

- Related to this is the involvement of the learner in this 'living' curriculum as the key driver.

- Recognising that knowledge and skill acquisition, and learning are separate processes and need different approaches;

- Identification of learning activities/processes by the learner not just the teacher.

- Using action research and action learning as meta-methodologies in the learning experience. 
- Involvement of the learner in the design of assessment, self-diagnosis and application of knowledge in real life contexts.

- Collaborative learning;

- Coaching for individual learning needs and application.

There are two main agendas in our current work with heutagogy. The first of these is to investigate through a focused research program whether or not heutagogy is a useful concept. Some initial research is mentioned above but there is more to do yet. It is surprising to see heutagogy spring up in so many places such as curricula documents and theory papers despite only a modicum of good research evidence to support it. Mind you, this should not discourage thinking at a theoretical level. The second agenda, which may be related to the first, is to understand further how learning takes place in complex adaptive systems and then how to harness and facilitate these processes.

\section{References}

Ackoff, R .L. and Emery, F.E. 1972. On purposeful systems. Chicago: Aldine.

Albon, R 2000. Motivation, dialogue and heutagogy: Driving collaborative assessment online, proceedings of the Education and Technology Conference, IEET, Calgary, June 17-19.

Ashton, J and Newman, L. 2006. An unfinished symphony: $21^{\text {st }}$ century teacher education using knowledge creating heutagogies, British Journal of Educational Technology, 37 (6): 825-840.

Bangura, A.K. 2004. Turbyi in the Muslim world with a focus in Saudi Arabia, paper presented at the United States Agency for International Development Conference on Education in Islamic Countries, Washington, Nov 9.

Bertalanffy, L von 1950. The theory of open systems in physics and biology. Science, 3: 22-29.

Coughlan, R. 2004, From the challenge to the response, proceedings of the BiTE Project Conference, Adastral Park, December.

Davis, B., and Sumara, D. 1997. Cognition, complexity and teacher education. Harvard Educational Review, 671: 105-125.

Doll, W. E. 1989. Foundations for a post-modern curriculum. Journal of Curriculum Studies, 21 (3): 243-253

Doolittle, P. E. 2000. Complex Constructivism: A theoretical model of complexity and cognition: Draft. Available: http:/ / www.tandl.vt.edu/doolittle/ research/complex1. html. Accessed April 302007.

Eberle, J. and Childress, M. 2007. Heutagogy: It isn't your mothers pedagogy any more, New Science Association, Available: www.nssa.us/journals/2007-81/2007-28-1.04.htm. Accessed $4^{\text {th }}$ May 2007.

Emery, F. and Trist, E. 1965. The causal texture of organisations, Human Relations, 18: $21-32$.

Emery, F.E. Ed.. 1976-1981. Systems thinking Vols. 1-2. Harmondsworth, Middlesex: Penguin. 
Gardiner, A, Hase, S., Gardner, G., Dunn, S. and Carryer, J. 2007. Nurse practitioner competence and capability, Journal of Clinical Nursing, In press.

Hase, S. 2002a. Complexity and heutagogy, invited paper at a symposium held at Middlesex University, UK.

Hase, S. 2002b. Simplicity in complexity: Capable people and capable organisations need each other, paper presented at the Australian Vocational Education and Training Association conference, Melbourne, April.

Hase, S. 2004. Action research in the workplace, pedagogy or pragmatism? That is the question, paper presented at a symposium held for the Work and Learning Network, University of Alberta, October.

Hase, S, Tay, B. H., and Goh, E. 2006. Developing management skill using action research: moving beyond skills and competency, paper presented at the Hawaian International Business Conference, Honolulu, May.

Hase, S, Tay, B. H., and Goh, E. 2006. Developing learner capability through action research: from pedagogy to heutagogy in the workplace, paper presented at the Australian Vocational Education and Training Research Association Conference, Woollongong, April.

Hase, S., and Davis, L., 1999. Developing capable employees: The work activity briefing, Journal of Workplace Learning, 8: 35-42.

Hase, S., and Kenyon, C., 2000 From andragogy to heutagogy, Ultibase, RMIT, Dec. Available, http://ultibase.rmit.edu.au/Articles/dec00/hase2.htm. Accessed April 302007.

Hase, S. and Tay, Boon Hou 2004. Capability for complex systems: Beyond competence, proceedings of Systems Engineering / Test and Evaluation Conference, SETE 2004, Focussing on Project Success, Adelaide, 8 to 10 November, CD-ROM

Hase, S. and Kenyon, C. 2003. Heutagogy and developing capable people and capable workplaces: Strategies for dealing with complexity, proceedings of The Changing Face of Work and Learning conference, Alberta, Sept 25-27.

Idrus, R. M. and McComas, K. 2006. Technology: Facilitating the transformation of learning, paper presented at the $3^{\text {rd }}$ International Conference on e-learning for the Knowledge Based Sociatey, Bangkok, August 3-4.

Ivan, S. 2006. When I grow up I want to be a registrar, paper presented at the ARUCC, Montreal.

Kavanagh, M. and Nicol, J. 2006. Creativity or conformity? Building Cultures of Creativity in Higher Education Conference, Cardiff, Oct.

Kenyon, C and Hase, S. 2001. Moving From Andragogy to heutagogy: Implications for $V E T$, paper presented at the AVETRA conference, Adelaide, March.

Keogh, M. 2005, Relationships not technology are the kyes to online learning, Available at www.odloa.org/events/2005conf/naref/odloa2005.keogh.pdf. Accessed April 302007.

Knowles, M. 1970 The modern practice of adult education: Andragogy versus pedagogy, New York: Associated Press.

Long, D. 1990. Learner managed learning: the key to life long learning and development, New York: Kogan Page.

Olliges, R. and Mahfood, S. 2004. Learned" in 60-Seconds: Assessment of Applied Andragogy in Credentialling Institutions "Learned" in 60-Seconds: Assessment of 
Applied Andragogy in Credentialing Institutions, SOPHE.

Phelps, R , Hase, S., and Ellis, A. 2005. Competency, capability, complexity and computers: Exploring a new model for conceptualising end-user computer education. British Journal of Educational Technology, 36, (1): 67-85.

Phelps, R. and Hase S., 2002 Complexity and action research: Exploring the theoretical and methodological connection, Educational Action Research, 103: 503-519.

Phelps, R., Ellis, A. and Hase, S. 2002 The role of metacognitive and reflective learning processes in developing capable computer users, paper presented at Meeting at the Crossroads: Proceedings of the 18th Annual Conference of ASCILITE, December 9-12: 481-490.

Sankaran, S, Hase, S, Dick, B. and Davies, A.T. 2007. Singing different tunes from the same song sheet: four perspectives of teaching the doing of action research, invited paper for special edition of Action Research, in press.

Sankaran, S., Hase, S. Dick, B. and Davies, A. 2006. Reflections on developing an offshore, action research/ learning-based PhD program, Action Learning Research and Practice, 3 (2): 197-211.

Stephenson, J. 1994 Capability and Competence: Are they the same and does it matter? Capability, 1 (1): 3-4.

Tay, B. H. and Hase, S. 2004, Role of action research in workplace PhDs, Research in Action Learning and Action Research Journal ALAR, 9 (1): 81-92.

Wilmott, G. and Barry, C. 2002. How does learning best occur in VET? What is some of the emerging thinking about VET pedagogy? Paper presented for NSW TAFE Commission Directors Strategic Directions Workshop, Sydney, Nov 8.

\section{About the Authors}

Chris Kenyon has many years experience as a senior consultant and educator. He has been director of two consulting organisations, and has worked with private companies and government departments in Australia, New Zealand, Zambia, Saudi Arabia, USA, Thailand and Malaysia. His book on cross-cultural communication was a recommended text in many university courses, and for six years he ran the "Strategies for Success" seminars designed to enhance the performance of senior executives. He was director of an MBA level program for ten years, and is still a guest presenter on a number of postgraduate courses. With Dr Stewart Hase in 2000, he introduced Heutagogy as a new approach to learning.

Stewart Hase is an academic, psychologist and psychotherapist, educator and consultant. Until the end of 2007 he is employed at Southern Cross University in the Graduate College of Management, in Northern NSW, Australia, where he has been for 19 years. At the end of the year he is going into semi-retirement and will pursue other interests as well as consulting should he be able to find anyone to drag him away from golf, fishing, surfing, walking, reading and writing. It's tough but someone has to do it!. [e-mail: stewart.hase@scu.edu.au] 
Heutagogy

(C) Copyright 2007. The authorS, Stewart Hase and Chris Kenyon, assign to the University of Alberta and other educational and non-profit institutions a non-exclusive license to use this document for personal use and in courses of instruction provided that the article is used in full and this copyright statement is reproduced. The authors also grant a non-exclusive license to the University of Alberta to publish this document in full on the World Wide Web, and for the document to be published on mirrors on the World Wide Web. Any other usage is prohibited without the express permission of the authors. 